\title{
Scorbut and purpuric hyperkeratotic skin lesions in the elderly: What relationship? A case report
}

\section{Binan Yves', Kassi Komenan², Konan N'guessan', Acko Ubrich'1, Kaba Ibrahima', Bita Darius, Adom Hilaire', Toutou Toussaint ${ }^{1}$}

\author{
${ }^{1}$ Department of Internal Medicine and Geriatrics, University Hospital Center (UHC)-Treichville, Abidjan, Cote d'Ivoire, \\ ${ }^{2}$ Department of Dermatology and Venerology, Training And Research Unit of Medical Sciences, University of Felix \\ Houphouet Boigny of Abidjan, Côte d'Ivoire
}

Corresponding author: Dr. Kassi Komenan, E-mail: siskakomlo@yahoo.fr

\begin{abstract}
Gingival bleeding and dental heaving during scurvy are the most reported in the literature. However nonspecific isolated purely cutaneous manifestations due to hypovitaminosis $\mathrm{C}$ are not uncommon. Their incidence increases with age related to decrease in microcirculation of the skin leading to trophic disorders observed in the skin extremities in the elderly. Here we report the case of an elderly with poly vascular disorders aged of 73 years old in whom we observed purpuric hyperkeratotic lesions on the extremities. The various paraclinical examinations and blood checks for different diagnostic hypotheses have helped to spread a disease of cholesterol emboli, systemic vasculitis and retain low vitamin $\mathrm{C}$ after dosing the ascorbic acid serum incidentally. The disappearance of these skin lesions after two weeks of oral vitamin $\mathrm{C}$ supplementation confirmed the diagnosis scorbut. The occurrence of mucocutaneous lesions in elderly with high risk of atherosclerosis and living in unfavorable socio-economic conditions must alert the clinician to look for low vitamin $\mathrm{C}$ and titrate the serum ascorbic acid.
\end{abstract}

Key words: Hypovitaminosis C; Ascorbic acid serum; Purpuric hyperkeratotic lesions; Elderly; Atherosclerosis

\section{INTRODUCTION}

Vitamin C is supplied exogenously by diet in human, primate and some animals. Vitamin $\mathrm{C}$ level decreases with age, especially in the epidermis [1,2]. This abnormality is responsible of diseases and the best known is scurvy which occurs when the value of ascorbic acid level is less than $6 \mu \mathrm{mol} / \mathrm{l}$. However, there are isolated specific manifestations purely Cutaneous in Hypovitaminosis $\mathrm{C}$ that are rarely described in the literature. They are a kind of follicular hyperkeratosis, pigmented icthyosis, healing delays and/or even venous ulcers [3]. In addition, during human aging a reflex in skin vasodilatation decreases $[4,5]$. This reduces microcirculation of the skin leading to trophic disorders observed in the skin extremities in the elderly. Furthermore, vitamin $\mathrm{C}$ supplementation improves skin blood flow [6]. We report a case of vitamin C deficiency in a septuagenarian revealed by purpuric hyperkeratotic lesions treated in fifteen days by vitamin C supplementation taken orally.

\section{CASE REPORT}

A 73-year-old-man, Guadeloupean, bachelor and retired is addressed in consultation in internal medicine for the fortuitous discovery of a monoclonal peak with light kappa chain associated with acrorhigosis and paresthesia of the feet. The clinical manifestations have been evolving for a year. Personal medical history revealed: hypertension known and treated since 1998 by quadritherapy (ACEBUTOLOL-200MG AMLOR® 5MG 3-CoAprovel@ 300/5MG), a tobacco intoxication weaned in 1967, a dyslipidemia treated since 2002 by Crestor, ischemic stroke that occurred in 2002 without sequelae. On admission time, we noted a blood pressure

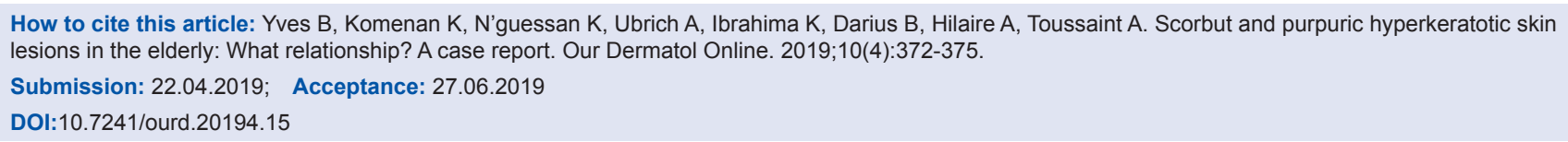


level of $135 / 80 \mathrm{mmHg}$ and a heart rate of $76 / \mathrm{min}$, pedal pulses were abolished on the left, decreased on the right as well as tibioposterior pulses. Both right and left femoral pulses were well perceived. There is no breath on auscultation of arterial axes but the local state of the foot showed a very poor venous condition of the lower limbs and especially distal ischemic lesions in all areas of support points, toes and the sole associated with acrocyanosis and painful stasis and distal ulcerations. The rest of the physical examination was normal.

Biological examinations showed a normal blood count, normal blood and urine electrolytes, and creatinine clearance decreased to $44 \mathrm{ml} /$ minute.

Serological tests such as, HIV, HBs Ag, HCV-Ag, Syphilis, Epstein-Barr virus, HTLV-1 and HTLV2 virus's tests were negatives, but HBs-Ag, HCV-Ag serological tests were positives, which were an evidence of an old virus infection.

Immunological tests, anti-nuclear, native anti DNA, and anti Beta2 GPl antibodies tests were negatives and presence of anti Cardiolipin antibodies with IgM positive to 54 units.

Additional tests carried out showed the existence of cataract in the right eye fundus and a clear glass with the slit lamp without cholesterol embolus. But, there was a retro- fovea serous retinal detachment of the left eye, without cholesterol embolus.

A skin biopsy of the left first metatarsal root showed a normal thickness of the epidermis, a discrete vascular dilation without vasculitis or thrombosis. The direct Immuno-Fluorescence examination was negative.

Capillaroscopy showed the absence of abnormality, organic microangiopathy.

The other morphological examinations were unremarkable except the echocardiography that revealed a concentric LV cardiomyopathy with an ejection fraction of $65 \%$.

Fortuitously, by dosing vitamin $\mathrm{C}$ level we noted hypovitaminosis in ascorbic acid estimated at 8.18 $\mu \mathrm{mol} / \mathrm{l}$ (technique used: HPLC electrochemistry, laboratory standard: $45-95 \mathrm{~m} / \mathrm{dl}$ ). We gave a vitamin $\mathrm{C}$ supplementation for a two-week period. Skin lesions that have been developing for about 1 year were healed and cleaned.

\section{DISCUSSION}

The degree of vitamin C deficiency should be defined. A rate over $26 \mu \mathrm{mol} / \mathrm{l}$ is considered normal; a rate between $6 \mu \mathrm{mol} / \mathrm{l}$ and $26 \mu \mathrm{mol} / \mathrm{l}$ represents Hypovitaminosis $\mathrm{C}$, which is known as severe if the rate is less than $13 \mu \mathrm{mol} / \mathrm{l}$. A rate under $6 \mu \mathrm{mol} / \mathrm{l}$ defines a deficiency. And scurvy is defined when the rate is under $6 \mu \mathrm{mol} / \mathrm{l}$ associated with clinical signs. Our patient had ascorbemia to $8.18 \mu \mathrm{mol} / \mathrm{l}$ therefore severe Hypovitaminosis C.

The prevalence of Hypovitaminosis $\mathrm{C}$ is common in men and increases with age, as observed in our patient. A study of 1108 outpatients in the region of Paris [7] highlighted an ascorbemia less than $2 \mathrm{mg} / \mathrm{l}$ in $5 \%$ of women and in $12 \%$ of men, reaching $15 \%$ of women and $20 \%$ of men in age group over 65 years. In the united kingdom in 1970, the studies showed that $50 \%$ of elderly people living at home had ascorbemia less than $2 \mathrm{mg} / \mathrm{l}[5]$.

A number of vitamin $\mathrm{C}$ deficiency risk factors have been identified in the study of Fain et al: the elderly, male gender, being retired or unemployed, having an infectious diseases and excessive consumption of alcohol and tobacco [3]. In our case, the patient was aged of 72 years old, single, retired and former smoker. These risk factors represents limiting factors of vitamin $\mathrm{C}$ absorption in the body. Moreover, the body stores of vitamin $\mathrm{C}$ are low (1500 mg) [8] so that the clinical picture of scurvy appears in one to three months of absolute deficiency of ascorbic acid when the total pool of the organism is under 300 $\mathrm{mg}$ and the ascorbic acid level falls below 2 [9] to $2.5 \mathrm{mg} / \mathrm{l}$ [3] Fain $\mathrm{O}$ and al. The patient had no scurvy but, Hypovitaminosis $\mathrm{C}$ with severe acrocyanosis of the extremities of the lower limbs. These skin lesions of typical acrorhigosis of chronic evolution (Fig. 1) on a constitutional susceptibility of preexisting vascular pathologies such as hypertension, ischemic stroke, Dyslipidemia, moderate renal impairment and former smoker in our patient allowed us to discuss the disease of cholesterol embolism; With the presence of a hyper eosinophilia to 572 cells $/ \mathrm{mm}^{3}$. But the absence of micro-crystals of cholesterol in the urine, in the eye fundus and skin biopsy were not in favor to the diagnosis.

The search for ANCA vasculitis, connective and cryoglobulinaemia were negative. Finally we retained, vitamin $\mathrm{C}$ deficiency with ascorbemia equal to $8.18 \mu \mathrm{mol} / \mathrm{l}$ revealed by a clinical picture of acrorhigosis 
with paresthesia of the feet that has been developing. Indeed Several studies showed that the presence of clinical signs of deficiency leading to a determination of ascorbemia, highlights Hypovitaminosis almost systematically [10-12] and up to $100 \%$ in the population of Oguike [13] and 93\% in Sentenac [14] although it is known that skin symptoms during vitamin $\mathrm{C}$ deficiency is extremely polymorphic and non-specific [3]. Purpuric hyperkeratotic lesions of extremities of limbs are rarely described unlike leg ulcers.

Vitamin $\mathrm{C}$ is involved in the synthesis of collagen as an essential cofactor for proline and lysine oxidase responsible for the formation of stable collagen helices. Vitamin $\mathrm{C}$ deficiency induces an alteration of the collagen structure [15]. There are 3 types of collagen including type 3 that is present in the skin and blood vessels. However, the amount of vitamin $\mathrm{C}$ is low in the elderly skin, particularly in the epidermis $[1,2]$ and the majority of the patients were at risk for atherosclerosis

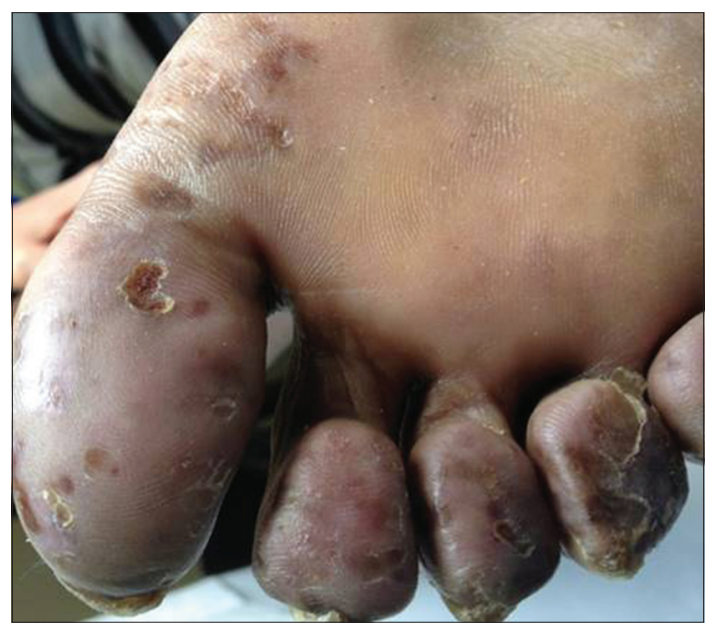

Figure 1: The sole of the foot before treatment.

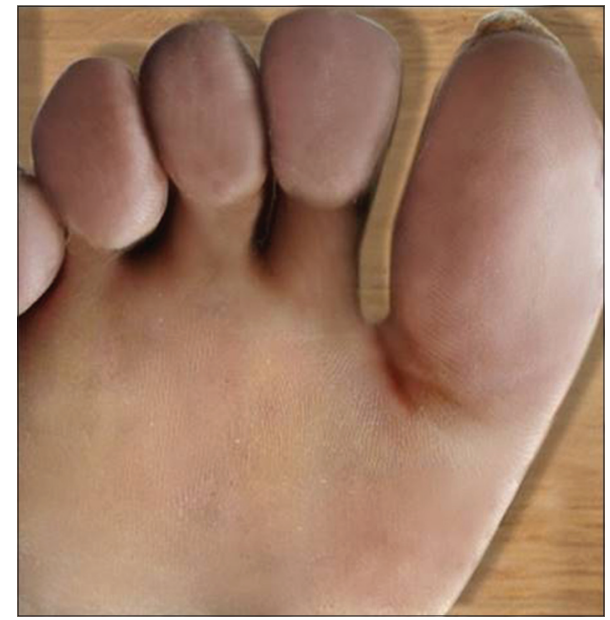

Figure 2: The sole of the foot after treatment. as in our patient. But, in patients with atherosclerosis, there is biochemical evidence that indicates the increase of oxidative stress resulting from a change in the balance of pro- and endogenous antioxidants [4]. This oxidative stress is associated with increased consumption of vitamin $\mathrm{C}$.

In short, the vitamin $\mathrm{C}$ deficiency in the epidermis of the elderly associated with atherosclerosis and inadequate vitamin $\mathrm{C}$ intake are risk factors when combined and could lead to skin lesions like those observed in our patient.

The oxidative attack of lens proteins was also considered as a risk factor for cataract. In the literature there is no consensus on the correlation between vitamin $\mathrm{C}$ status and the frequency of cataracts. Some studies evoked a relationship between poor intakes of vitamin $\mathrm{C}$ and cataract, but others [16] did not find any correlation. Cataract found in our patient, however, can be related to severe low vitamin C.

The favorable outcome characterized by the disappearance of purpuric hyperkeratotic lesions (Fig. 2) by supplementing $1 \mathrm{~g}$ /day of ascorbic acid in our patient orally for two weeks demonstrated retrospectively the validity of the diagnosis.

\section{CONCLUSION}

The appearance of mucocutaneous lesions in geriatric subject with high risk of atherosclerosis and living in low socio-economic conditions should directed the clinician to the diagnosis of Hypovitaminosis $\mathrm{C}$ and to determine the ascorbic acid level.

The dosage of vitamin $\mathrm{C}$ level is expensive and difficult; therefore prevention of Hypovitaminosis $\mathrm{C}$ by daily supplementation in the diet of the Geriatric subject by the consumption of fruits and vegetables should be advocated.

\section{Acknowldgements}

We would like to knowledge all health practitioner from the teaching hospital of Treichville/Abidjan/Cote d'Ivoire.

\section{Consent}

The examination of the patient was conducted according to the Declaration of Helsinki principles. 


\section{REFERENCES}

1. Leveque N, Muret P, Mary S, Makki S, Kantelip JP, Rougier A, et al. Decrease in skin ascorbic acid concentration with age. Eur J Dermatol. 2002;12:21-2.

2. Leveque N, Robin S, Makki S, Muret P, Rougier A, Humbert P. Iron and ascorbic acid concentrations in human dermis with regard to age and body sites. Gerontology. 2003;49:117-22.

3. Fain O, Pariés J, Jacquart B, Le Moël G. Hypovitaminosis C in hospitalized patients. Eur J Intern Med. 2003;14:419-25.

4. Kenney WL. Control of heat-induced cutaneous vasodilatation in relation to age. Eur J Appl Physiol Occup Physiol. 1988;57 120-5.

5. Kellogg DL Jr, Pergola PE, Piest KL, Kosiba WA, Crandall CG, Grossmann M, et al. Cutaneous active vasodilation in humans is mediated by cholinergic nerve cotransmission. Circ Res. 1995; $77: 1222-8$

6. Jennifer J, DuPont, William B, Farquhar, Raymond R. Townsend. Ascorbic acid or l-arginine improves cutaneous microvascular function in chronic kidney disease. J Appl Physiol. 2011;111:1561-7.

7. Hercberg S, Preziosi P, Galan P, Deheeger M. Vitamin status of a healthy french population: dietary intakes and biochemical markers. Int J Vitamin Nutr Res. 1994;64:220-3.

8. Lazareth I, Hubert S, Michon-Pasturel U, Priollet PJ. Vitamin C deficiency and leg ulcers. A case control study. Mal Vasc. 2007; 32:96-9.

9. Johnstan CS, Thompson LL. Vitamin C status of an outpatient population. J Am Coll Nutr. 1998;17:366-70.

10. Blateau S. Scorbut et déficit en vitamine C: étude rétrospective à propos de 164 cas [Thèse d'exercice]. 2005. Université de Reims Champagne-Ardenne.

11. Le Bris T. Quel est l'intérêt de l'ascorbémie dans le diagnostic et le traitement [Thèse d'exercice]. [France]: Université de Caen UFR de médecine; 2012. 61. Raynaud-Simon. Scurvy in hospitalized elderly patients, 20617280.

12. Malmauret L, Leblanc J, Cuvelier I, Verger P. Dietary intakes and vitamin status of a sample of homeless people in Paris. Eur J Clin Nutr. 2002;56:313-20.

13. Oguike M. Scorbut et précarité, prévalence d'une maladie oubliée en médecine générale [Thèse d'exercice]. Université de Montpellier I. 2014. Faculté de Médecine.

14. Sentenac G. Le scorbut au XXIème siècle, une nouvelle maladie ? [Thèse d'exercice]. 2016. Université Rouen: UFR de Médecine.

15. Carr Ac, Frei B. Toward a new recommended dietary allowance for vitamin $\mathrm{C}$ based on antioxydant and health effects in humans. Am J Clin Nutr. 1999;69:1086-107.

16. Vitale S, West S, Hallfrisch J, Alston C, Wang F, Moorman C, et al. Plasma antioxidants and risk of cortical and nuclear cataract. Epidemiology. 1993;4:195-203.

Copyright by Binan Yves, et al. This is an open-access article distributed under the terms of the Creative Commons Attribution License, which permits unrestricted use, distribution, and reproduction in any medium, provided the original author and source are credited.

Source of Support: Nil, Conflict of Interest: None declared. 